\title{
UTERINE FIBROIDS IN EARLY REPRODUCTIVE AGE WOMEN: FEATURES OF MORPHOLOGY, HORMONAL STATUS AND REHABILITATION
}

\author{
Serhii Vdovichenko', Anna Bober ${ }^{2}$, Oleksandra Lubkovska ${ }^{3}$, Vitalii Strakhovetskyi ${ }^{4}$ \\ ${ }^{1}$ Department of Obstetrics, Gynecology and Perinatology, Ukrainian State Institute of Reproductology, Shupyk National Medical \\ Academy of Postgraduate Education, Kyiv, Ukraine, 04112 \\ ORCID: http://orcid.org/0000-0002-9205-510X \\ ${ }^{2}$ Department of Obstetrics, Gynecology and Perinatology, Ukrainian State Institute of Reproductology, Shupyk National Medical Academy \\ of Postgraduate Education, Kyiv, Ukraine, 04112 \\ ORCID: http://orcid.org/0000-0001-7157-9628 \\ ${ }^{3}$ Department of Obstetrics, Gynecology and Perinatology, Ukrainian State Institute of Reproductology, Shupyk National Medical Academy \\ of Postgraduate Education, Kyiv, Ukraine, 04112 \\ ORCID: http://orcid.org/0000-0002-4522-0723 \\ ${ }^{4}$ Department of Endoscopy and Surgery, Kharkiv Medical Academy of Postgraduate Education, Kharkiv, Ukraine \\ ORCID: http://orcid.org/0000-0001-7589-7383
}

A RT ICLE INF O
Article history:
Received date 11.01 .2021
Accepted date 24.02 .2021
Published date 28.02 .2021
Section:
Practical medicine
D O I
10.21303/2313-8416.2021.001680
K E Y W O R D S

uterine fibroids

early reproductive age

combined oral contraception

antigonadotropin releasing hormone

hormonal status

\section{ABSTRACT}

The object of the study: Uterine fibroids (UF) in women of early reproductive age.

The problem to be solved: Improving the effectiveness of postoperative rehabilitation in women of early reproductive age with uterine fibroids based on the study of its morphological features and improvement of rehabilitation measures.

The main scientific results: It was found that in women of early reproductive age with UF the most common complaints are posthemorrhagic anemia ( $61.0 \%$, or 61 women). Regarding the menstrual cycle, the most common dysmenorrhea - $26.0 \%$ (in 26 women). The importance of heredity in the development of such pathology in young women $(32.0 \%$, or 32 women) was confirmed. The most common localization of fibroids is interstitial $79.0 \%$ (in 79 women).

Morphological study found that women of early reproductive age most often have a simple UF, namely $96 \%$ (96 women). Uterine leiomyoma was present in $56 \%$ (56 women).

A study of the hormonal status of women of early reproductive age found that the mean values of hormones such as follicle-stimulating hormone (FSH), luteinizing hormone (LH), estradiol, progesterone, prolactin and testosterone were higher before surgery than after. When comparing rehabilitation methods (combined oral contraceptives (COCs) or gonadotropin-releasing hormone agonists (GnRH agonists), it was found that postoperative rehabilitation by using COCs for 6-12 months provides significantly better indicators of recovery of hormonal status, indicating the effectiveness of rehabilitation method.

Scope of practical application of research results: Practical medicine specializing in the diagnosis, treatment and prevention of recurrence of uterine fibroids.

Innovative technological product: Improved algorithm of postoperative rehabilitation measures by applying COC for 6-12 months after myomectomy, which provides significantly better results in restoring hormonal status during rehabilitation.

Scope of application of innovative technological product: clinical medical practice related to the diagnosis, treatment and prevention of recurrence of uterine fibroids.

(C) The Author(s) 2021. This is an open access article under the CC BY license http://creativecommons.org/licenses/by/4.0).

\section{Introduction}

\section{1. The object of the research}

The object of the study is uterine fibroids in women of early reproductive age.

\section{2. Problem description}

Uterine fibroids are among the most common benign tumors of the pelvic organs, which occurs in women of all ethnic groups. In women under the age of 35, the frequency of UF is almost $60 \%$, in women under the age of $50-80 \%$ and its prevalence increases every year, especially in women of early reproductive age $[1,2]$. 
For a long time, women with UF may have no complaints and find it by accident. The main complications that accompany UF are irregular, prolonged bleeding, anemia, chronic pelvic pain, reproductive dysfunction, in particular, difficulty conceiving, miscarriage and infertility [3, 4].

There are a number of aspects that may be the causes of such pathology. These include hormonal, immunological, molecular genetic. In addition, factors that can trigger UF growth include age, race, obesity, pelvic infections, and lifestyle, namely alcohol consumption, smoking, constant stress, excessive exercise, a diet depleted of vitamins, and so on [5].

The hormonal theory of UF development is hyperestrogenism, progesterone deficiency and hypergonadotropism. In turn, the immunological theory of the pathogenesis of UF lies in the imbalance controlling the proliferative process of immune mechanisms, which can cause the development of such pathology, as well as accelerate the growth of fibroids $[6,7]$.

\subsection{Proposed way to solve the problem}

Special attention is paid to the treatment of patients with UF, in particular, women of early reproductive age, because this pathology adversely affects the reproductive function and general health of women. Such women should be treated as early as possible, immediately after diagnosis, because passive monitoring of them leads to disease progression. The main methods of therapy include hormonal and surgical treatment, with the latter becoming more and more common. Given the high frequency of recurrences and the desire of women to maintain reproductive function, treatment and prevention measures, as well as postoperative rehabilitation using hormonal correction to reduce recurrences are the basis of modern medicine. Therefore, the study of morphological features of UF and hormonal status before surgery and after hormonal correction in the postoperative period for rehabilitation is relevant.

The aim - improving the effectiveness of postoperative rehabilitation in women of early reproductive age with uterine fibroids based on the study of its morphological features and improvement of rehabilitation measures.

\section{Materials and methods}

The study was conducted from 2018 to 2020 on the basis of the Department of Obstetrics, Gynecology and Perinatology of the National Medical Academy of Postgraduate Education named after P. L. Shupyk on the basis of the Kyiv Maternity Hospital No. 1 (gynecological department). 150 women were selected for the study. Of these, 100 women under the age of 30 formed the main group (1), whose average age was $27.2 \pm 2.5$ years. Inclusion criteria were age up to 30 years and the presence of UF with indications for surgical treatment. Exclusion criteria were age over 30 years, lack of UF, malignant neoplasms of the uterus. The other 50 women aged 40 to 50 years formed a control group (2). Their mean age was $45.5 \pm 3.7$ years $(P<0.05$ relative to the main group). Inclusion criteria were age $40-50$ years and the presence of UF with indications for surgical treatment. Exclusion criteria were age less than 40 years and more than 50 years, absence of UF, as well as malignant neoplasms of the uterus.

The study collected a history of women with the presence of UF in relatives to determine the role of heredity in its development. In addition, their complaints were collected and analyzed, the general condition was assessed, a gynecological examination was performed, during which the cervix, vagina, uterine size were examined, and the presence of myomas, their number and size were determined. An ultrasound examination was also performed using an ultrasound machine "GE Logiq F8" (Germany). Abdominal scan (for large tumors) allowed to obtain screening information about the condition of the uterus, the size and location of myomas, the relationship of nodes to adjacent organs, main vessels. Transvaginal scanning provided even more detailed information on the size and topography of the nodes.

Morphological studies were performed as follows: 3-4 fragments of tumor tissue and fragments of the adjacent myometrium were taken from each myomatous node; the material was fixed in $10 \%$ buffered formalin, then wired; paraffin sections $4 \mu \mathrm{m}$ thick were stained with hematoxylin and eosin [8].

Also, in order to determine a more effective method of rehabilitation, in particular to reduce the recurrence rate of UF, the main group was divided into two subgroups: 1.1 - 50 women who were prescribed COC for 6-12 months, and 1. 2-50 women who took GnRH agonists for 3 months.

The hormonal status of the main group of women was assessed by determining hormones such as FSH, LH, estradiol, progesterone, prolactin and testosterone, electrochemiluminescent detection 
(ECLIA) immunochemical method on a Sobas 6000 analyzer, using Roche Diagnost test systems (Switzerland). To determine all hormonal parameters, venous blood was taken on day 5-7 of the menstrual cycle, except for progesterone, which was determined on day 20-21 of the menstrual cycle.

The study was conducted in accordance with the Declaration of Helsinki according to the conclusion of the Commission on Ethics of the National Medical Academy of Postgraduate Education named after P. L. Shupyk (minutes No. 3 from 11.01.2018). Informed consent to participate in the study was obtained from all women.

Statistical processing of the obtained data was performed using Statistica and Microsoft Office Excel. Evaluation of the statistical significance of the obtained data was performed using Student's t-test and criterion $X 2$, the differences were considered significant at $p<0.05$.

\section{Results}

After analysis, it was found that the average duration of the disease in patients from the main group was $3.3 \pm 0.3$ years, and the most frequent complaints according collected history were posthemorrhagic anemia ( $61.0 \%$, i.e. in 61 women), rapid growth of UF (51.0\%, i.e. in 51 women), pain syndrome ( $46.0 \%$, i.e. in 46 women), menstrual dysfunction ( $43.0 \%$, i.e. in 43 women), infertility (18.0\%, i.e. in 18 women) and habitual miscarriage (10.0\%, i.e. in 10 women) [9].

Because menstrual dysfunction adversely affects a woman's quality of life, on the one hand, and may be a factor in the development of other complications, including posthemorrhagic anemia, the frequency and nature of menstrual disorders in women of the main group were studied (Fig. 1). Thus, the most common dysmenorrhea $-26.0 \%$ or 26 women (relative to oligomenorrhea and polymenorrhea $\mathrm{p}<0.05$ ), less hypermenorrhea $-15 \%$ or 15 patients, polymenorrhea $-11 \%$ or 11 women, and the least common - oligomenorrhea - only in $7.0 \%$ or in 7 patients of the main group.

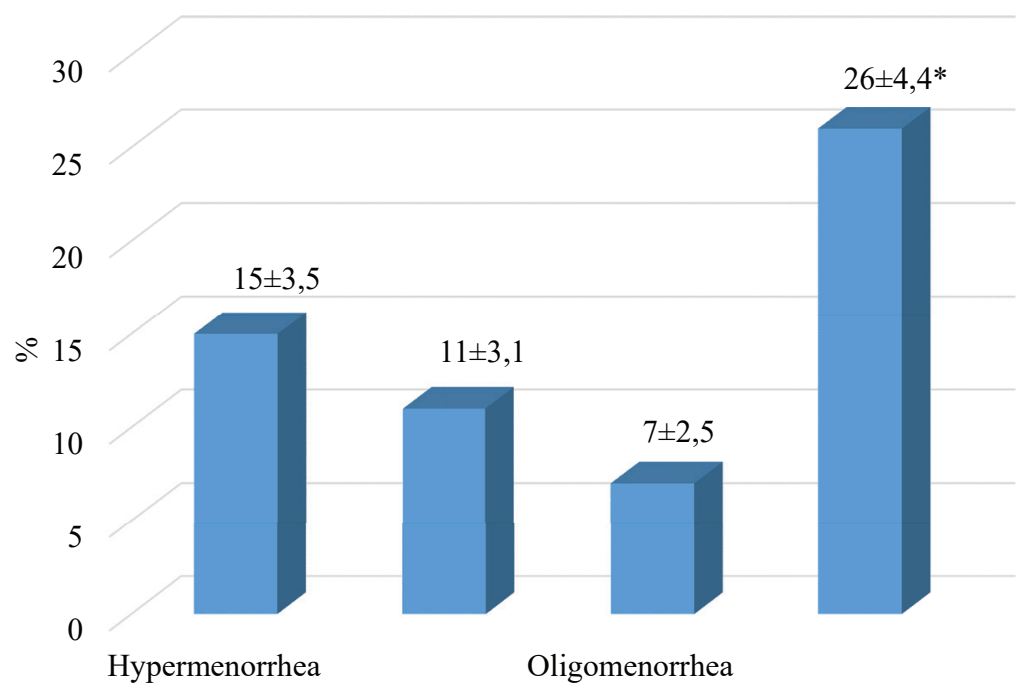

Fig. 1. Frequency and nature of menstrual disorders in women of the main group: * regarding oligomenorrhea and polymenorrhea $\mathrm{p}<0.05$

Given the important role in the development of UF plays heredity, so also in women of the main group was studied the aspect of heredity. Thus, $32.0 \%$ of patients (ie, 32 women) (uterine fibroids under the age of 30) had a burdened heredity for the development of UF. Moreover, in $19.0 \%$ of patients (ie 19 women) it was the first degree of kinship (fibroids in the mother or sister), in $5.0 \%$ of women (ie 5 women) - the second degree (UF in the grandmother), in $6.0 \%$ (ie 6 women) - III degree of kinship (aunt), $2.0 \%$ (ie 2 women) - IV degree of kinship (cousin). The obtained data confirm the importance of genetic theory in the development of UF.

In addition, an important aspect is the localization of fibroids. During the ultrasound it was found that the most common interstitial nodes, namely in 79 women $(79.0 \%)$, in 24 women $(24.0 \%)$ there were subserous-interstitial nodes, interstitial with centrifugal growth were in 22 women $(22.0 \%)$ and subserous in 17 women $(17.0 \%)$. In isolated cases, namely in 6 women $(6.0 \%)$ the presence of submucosal nodes was recorded. 
In order to determine the morphological type of UF and its features in women of early reproductive age, compared with UF in older women (control group), a morphological study was performed (Table 1).

Table 1

Morphological type of UF (\%)

\begin{tabular}{ccc}
\hline Indicators & Main group $\boldsymbol{n = 1 0 0}$ & Control group $\boldsymbol{n}=\mathbf{5 0}$ \\
\hline proliferating type of fibroids & $4.0 \pm 1.96$ & $6.0 \pm 4.59$ \\
mitotically active & $1.0 \pm 0.99$ & $2.0 \pm 2.77$ \\
cellular leiomyoma & $3.0 \pm 1.70$ & $4.0 \pm 3.83$ \\
simple type of fibroids & $96.0 \pm 1.96$ & $94.0 \pm 18.19$ \\
leiomyoma & $56.0 \pm 4.96$ & $54.0 \pm 4.16$ \\
chimerical & $3.0 \pm 1.70$ & 0 \\
hydropic & $11.0 \pm 3.13$ & $12.0 \pm 6.04$ \\
lipomatous & $1.0 \pm 0.99$ & $2.0 \pm 2.77$ \\
epithelioid & $1.0 \pm 0.99$ & 0 \\
vascular & $19.0 \pm 3.92$ & $24.0 \pm 7.06$
\end{tabular}

Note: for all indicators between the main and control groups $p>0.05$

It was found that proliferating and simple UF in the main group and control occurred with almost the same frequency: proliferating - respectively 4.0 and $6.0 \%$ (i.e. in 4 and 3 women), simple - 96.0 and $94.0 \%$ (96 and 47 women). Leiomyoma was most common in these groups: in the main group in $56.0 \%$ of women (in 56 women), and in the control group in $54.0 \%$ (in 27 women). Vascular type of fibroids, on the contrary, was more common in women of the control group - $24.0 \%$ (in 12 women), and in the main - $19.0 \%$ (in 19 women). Mitotically active type was in $2.0 \%$ of women (i.e. 1 woman) of the control group and $1.0 \%$ (i.e. 1 woman) of the main. In addition, in the control group was recorded cellular leiomyoma in $4.0 \%$ (in 2 women) of observations, in the main - in $3.0 \%$ (in 3 women). There were also lipomatous $-2.0 \%$ (in 1 woman) in women of the control group and $1.0 \%$ (in 1 woman) in the main, chimeric and epithelioid - respectively, $3.0 \%$ and $1.0 \%$ (in 3 and 1 women) only in the main. The hydropic type of fibroids was in $12.0 \%$ (in 6 patients) in the control group and in $11.0 \%$ (in 11 patients) in the main group. Leiomyoma with lymphoid infiltration was diagnosed in $2.0 \%$ of women in the control group and in $5.0 \%$ of the main group (i.e. in 1 and 5 women, respectively).

The nature of disorders in myomatous nodes was also studied. It was found that patients of the main group, compared with the control, were significantly more likely to have microcirculation disorders in the nodes $-43.0 \%$ vs. $12.0 \%$ (i.e., 43 and 6 women, respectively) $(p<0.001)$ (Table ). Hyalinosis of nodes, on the contrary, was significantly more frequent in the control group $-44.0 \%$ (in 22 women), i.e. in almost half of patients, while in the main - at $17.0 \%$ (in 17 women) $(p<0.001)$. Calcification of the nodes occurred with almost the same frequency in both groups $(p>0.05)$.

In order to determine the hormonal characteristics of women of early reproductive age with UF, as well as the impact of myomectomy on them, their hormonal status before and after surgery (6 months after its implementation in phase 1 of the menstrual cycle) was studied. In order to determine a more effective method of postoperative rehabilitation - COC or GnRH agonists, a comparison of hormonal status between the respective subgroups was also performed.

Table 2

The nature of disorders in myomas (\%)

\begin{tabular}{ccc}
\hline Indicators & Main group $\boldsymbol{n = 1 0 0}$ & Control group $\boldsymbol{n}=\mathbf{5 0}$ \\
\hline microcirculatory disorders in the nodes (circulatory disorders, edema, necrosis) & $43.0 \pm 4.95^{*}$ & $12.0 \pm 6.04$ \\
calcification of nodes & $1.0 \pm 0.99$ & $2.0 \pm 2.77$ \\
hyalinosis of nodes & $17.0 \pm 3.75^{*}$ & $44.0 \pm 4.59$
\end{tabular}

Note: * relative to the control group $p<0.001$

Data on the content of hormones in the blood of patients with UF before and 6 months after myomectomy are presented in Tables 3, 4 . 
Table 3

Levels of FSH, LH, estradiol, progesterone, prolactin, testosterone in the blood of patients of early reproductive age with UF before and after myomectomy with COC rehabilitation

\begin{tabular}{ccc}
\hline Indicators & Before the operation main group $\boldsymbol{n = 1 0 0}$ & After the operation subgroup 1. 1 $\boldsymbol{n}=\mathbf{5 0}$ \\
\hline FSH (MO/l) & $7.9 \pm 0.8$ & $6.5 \pm 0.5$ \\
LH (MO/l) & $7.4 \pm 0.7$ & $4.5 \pm 0.4^{*}$ \\
Estradiol (pmol/l) & $368.2 \pm 34.5$ & $251.0 \pm 24.8^{*}$ \\
Progesterone (nmol/1) & $6.5 \pm 0.6$ & $4.1 \pm 0.4^{*}$ \\
Prolactin (mIU/l) & $318.2 \pm 29.4$ & $301.0 \pm 28.7$ \\
Testosterone (nmol/l) & $2.2 \pm 0.2$ & $1.6 \pm 0.2^{*}$
\end{tabular}

Note: * relative to the indicators of the main group before the operation $p<0.05$

Table 4

Levels of FSH, LH, estradiol, progesterone, prolactin, testosterone in the blood of patients of early reproductive age with UF before and after myomectomy with rehabilitation of GnRH agonists

\begin{tabular}{ccc}
\hline Indicators & Before the operation main group $\boldsymbol{n = 1 0 0}$ & After the operation subgroup 1.2 $\boldsymbol{n}=\mathbf{5 0}$ \\
\hline FSH (MO/l) & $7.9 \pm 0.8$ & $7.3 \pm 0.7$ \\
LH (MO/l) & $7.4 \pm 0.7$ & $5.1 \pm 0.7^{*}$ \\
Estradiol (pmol/l) & $368.2 \pm 34.5$ & $327.8 \pm 30.5$ \\
Progesterone (nmol/l) & $6.5 \pm 0.6$ & $5.1 \pm 0.5$ \\
Prolactin $(\mathrm{mIU} / \mathrm{l})$ & $318.2 \pm 29.4$ & $311.0 \pm 27.5$ \\
Testosterone $(\mathrm{nmol} / \mathrm{l})$ & $2.2 \pm 0.2$ & $1.5 \pm 0.2^{*}$
\end{tabular}

Note: * relative to the indicators of the main group before the operation $p<0.05$

The presented data show that the average level of FSH before and after surgery was within normal values, but no significant effect of surgery was observed, including no significant differences between rehabilitation methods. At the same time, among women with COC rehabilitation, normal FSH levels were observed in $80.0 \%$ (40 women) of cases and only in $20.0 \%$ of patients (i.e. 10 women) it exceeded the normative values, while among women with GnRH rehabilitation agonists normal values of FSH levels after surgery were detected in $60.0 \%$ of cases (in 30 women), and in $40.0 \%$ (in 20 women) the FSH level exceeded the upper limit of normal. Regarding LH, after surgical treatment there was a statistically significant $(P<0.05)$ decrease in its level, and there was an increase in the number of women with normal values to $84.0 \%$ (42 women). At the same time, there was no significant difference in approaches to postoperative rehabilitation.

In turn, the mean values of estradiol after surgery showed a significant decrease $(p<0.05)$ in women with COC rehabilitation (normal values were in $84.0 \%$ of patients, namely in 42 patients), in contrast to the rehabilitation of GnRH agonists, when the differences between the mean values of this hormone before and after myomectomy did not differ significantly (indicators after surgery in $68.0 \%$ of women, i.e. in 34 patients, were within normal limits).

A similar situation occurred for progesterone, when COC rehabilitation provided better results, namely a statistically significant decrease after myomectomy of the average value of this hormone $(p<0.05)$, while among women with GnRH agonists rehabilitation, although there was a decrease in its average level but it was insignificant.

The average values of prolactin before and after surgery did not differ significantly, while the average level of testosterone, on the contrary, after myomectomy differed significantly in the direction of decrease $(p<0.05)$, which indicates the effectiveness of such treatment. However, there was no statistically significant difference directly between rehabilitation methods in terms of this hormone.

Therefore, from the analysis it is possible to observe higher efficiency of postoperative rehabilitation by use of COC (average values of LH, estradiol, progesterone and testosterone after operation and COC rehabilitation were significantly better than before myomectomy). Rehabilitation of GnRH agonists provides a slightly smaller effect, although, in general, also brings positive results (average values of LH and testosterone after myomectomy with rehabilitation of GnRH agonists were significantly better than before surgery).

\section{Discussion of research results}


The occurrence of UF, especially in early reproductive age, remains one of the main problems of modern medicine, because the complications it causes, especially infertility, affect not only a woman's reproductive health, but also her psychological state [10, 11]. According to the literature, the main risk factors for such pathology include chronic genital and extragenital diseases, bad habits, environmental hazards, frequent stress, irrational use of contraceptives and others. For early diagnosis of uterine fibroids in women of early reproductive age should pay attention to the implementation of reproductive function, heredity and the nature of the formation of menstrual function [12, 13].

It is known that, especially in early reproductive age, UF is characterized by various clinical manifestations $[14,15]$. It was found that the most common such manifestations were posthemorrhagic anemia, pain, menstrual dysfunction, infertility and habitual miscarriage. In terms of menstrual disorders, it was found that in women of early reproductive age the most common dysmenorrhea $26.0 \%$ (in 26 women), and the least - oligomenorrhea, which, despite the presence of UF, was observed in $7.0 \%$ of patients (in 7 women) of the main group.

Heredity plays an important role in the development of UF [16]. The results showed that some of the studied women of early reproductive age were burdened with heredity in the development of UF (32.0\%, or 32 women), in particular in one in five - $19.0 \%$ (19 women) - the first degree of kinship (mother, sister). The obtained data once again confirmed the importance of genetic theory in its development.

Another aspect of a disease such as UF is its adverse effects on a woman's reproductive health. In this context, its location plays an important role [17, 18]. When assessing the structure of localization of myomatous nodes in patients of the main group, it was found that interstitial nodes occurred in $79.0 \%$ of cases (in 79 women), subserous-interstitial - in $24.0 \%$ (in 24 women), interstellar with centrifugal growth - in $22.0 \%$ (in 22 women), subserous - in $17.0 \%$ (in 17 women), submucosal - in $6.0 \%$ (in 6 women).

Regarding the morphological structure, the most common simple type of fibroids: in the main group - $96 \%$ (96 women), in the control - $94 \%$ (47 women). Among them, leiomyoma was most often detected: in the main group - $56 \%$ (in 56 women), in the control - $54 \%$ (in 27 women). It was also found that women in the main group, compared with the control, significantly more common microcirculation disorders in the nodes ( $43.0 \%$ vs. $12.0 \%$, i.e. in 43 and 6 women, respectively, $p<0.001)$, and hyalinosis nodes, on the contrary, - in $17.0 \%$ in the main group against $44 \%$ in the control group (i.e. in 17 and 22 women, respectively, $p<0.001$ ).

It is known that one of the main methods of treatment is surgery. However, its effectiveness against relapses in the future depends on the right hormonal correction [19, 20]. Therefore, the hormonal status of women of early reproductive age was investigated and analyzed in order to determine a more optimal method of rehabilitation. The data showed that among women with COC rehabilitation in more patients normal FSH levels were observed, and only in $20.0 \%$ of patients (i.e. in 10 women) it exceeded the norm, while among women with GnRH agonists rehabilitation there was some the number of women with normal values $-60.0 \%$ (30 women) with $40.0 \%$ (20 women) with exceeding the upper limit of its norm. Regarding LH, there was no significant difference in approaches to postoperative rehabilitation. The mean values of estradiol and progesterone were significantly better in women with COC rehabilitation, in contrast to the other subgroup, where although there was a decrease in their mean values compared to myomectomy, but such a decrease was insignificant. The results also showed that in women of both the first subgroup and the second prolactin did not differ statistically before and after surgery. The picture of testosterone showed significantly better averages after rehabilitation by both methods.

Study limitations. The study was not performed in case of severe extragenital pathology.

Prospects for further research. Establishing the recurrence rate of uterine fibroids in women of early reproductive age among those receiving COC and GnRH agonists as rehabilitation, and determining the correlation between recurrence rate and reproductive function in women with these rehabilitation methods.

Study of the features of recurrence of uterine fibroids in women of early reproductive age in order to increase their reproductive function.

\section{Conclusions}

As a result of a study in women of early reproductive age with UF was found: 
1. The most frequent complaints are posthemorrhagic anemia (61.0\%, i.e. in 61 women); menstrual disorders are most often characterized by dysmenorrhea - $26.0 \%$ (in 26 women).

2. The most common localization of fibroids is interstitial - $79.0 \%$ (in 79 women).

3. By morphological type, simple UF is most common, namely $96 \%$ (in 96 women), with the frequency of uterine leiomyoma - $56 \%$ (in 56 women); impaired microcirculation in the nodes was in $43 \%$ (43 women).

4. Mean values of hormones such as FSH, LH, estradiol, progesterone, prolactin and testosterone were higher before surgery than after with appropriate rehabilitation.

5. Postoperative rehabilitation by using COC for 6-12 months after myomectomy provides significantly better results in restoring hormonal status ( $\mathrm{LH}$, estradiol, progesterone and testosterone), which indicates a higher efficiency of this method of rehabilitation, compared with GnRH agonists.

\section{Conflict of interest}

The authors declare that they have no conflicts of interest.

\section{References}

[1] Vilos, G. A., Allaire, C., Laberge, P.-Y., Leyland, N., Vilos, A. G., Murji, A., Chen, I. (2015). The Management of Uterine Leiomyomas. Journal of Obstetrics and Gynaecology Canada, 37 (2), 157-178. doi: http://doi.org/10.1016/s1701-2163(15)30338-8

[2] Bulun, S. E. (2013). Uterine Fibroids. New England Journal of Medicine, 369 (14), 1344-1355. doi: http://doi.org/10.1056/ nejmra1209993

[3] Doherty, L., Mutlu, L., Sinclair, D., Taylor, H. (2014). Uterine fibroids: clinical manifestations and contemporary management. Reproductive sciences, 21 (9), 1067-1092. doi: http://doi.org/10.1177/1933719114533728

[4] Zepiridis, L. I., Grimbizis, G. F., Tarlatzis, B. C. (2016). Infertility and uterine fibroids. Best Practice \& Research Clinical Obstetrics \& Gynaecology, 34, 66-73. doi: http://doi.org/10.1016/j.bpobgyn.2015.12.001

[5] Stewart, E., Cookson, C., Gandolfo, R., Schulze-Rath, R. (2017). Epidemiology of uterine fibroids: a systematic review. BJOG: An International Journal of Obstetrics \& Gynaecology, 124 (10), 1501-1512. doi: http://doi.org/10.1111/1471-0528.14640

[6] Reis, F. M., Bloise, E., Ortiga-Carvalho, T. M. (2016). Hormones and pathogenesis of uterine fibroids. Best Practice \& Research Clinical Obstetrics \& Gynaecology, 34, 13-24. doi: http://doi.org/10.1016/j.bpobgyn.2015.11.015

[7] Commandeur, A. E., Styer, A. K., Teixeira, J. M. (2015). Epidemiological and genetic clues for molecular mechanisms involved in uterine leiomyoma development and growth. Human Reproduction Update, 21 (5), 593-615. doi: http://oi.org/10.1093/ humupd/dmv030

[8] Bahrii, M. M., Dibrova, V. A., Hryshchuk, M. I. (2016). Metodyky morfolohichnykh doslidzhen. Vinnytsia: Nova knyha, 328.

[9] Bober, G. S. (2020). Profilaktyka retsydyviv u zhinok rannoho reproduktyvnoho viku z miomoiu matky. Reproductive health of woman, 3, 18-20.

[10] Rusanovskii, V. V., Blokh, M. E., ZHeleznov, I. A., Udodova, I. N., Rusanovskii, G. V. (2012). Psikhologicheskie osobennosti zhenschin s endometriozom i miomoi matki. Vestnik Orlovskogo gosudarstvennogo universiteta. Seriia: Novye gumanitarnye issledovaniia, 3, 131-135.

[11] Whynott, R., Vaught, K., Segars, J. (2017). The Effect of Uterine Fibroids on Infertility: A Systematic Review. Seminars in Reproductive Medicine, 35 (6), 523-532. doi: http://doi.org/10.1055/s-0037-1607295

[12] McWilliams, M., Chennathukuzhi, V. (2017). Recent Advances in Uterine Fibroid Etiology. Seminars in Reproductive Medicine, 35 (2), 181-189. doi: http://doi.org/10.1055/s-0037-1599090

[13] Rice, K. E., Secrist, J. R., Woodrow, E. L., Hallock, L. M., Neal, J. L. (2012). Etiology, Diagnosis, and Management of Uterine Leiomyomas. Journal of Midwifery \& Women's Health, 57 (3), 241-247. doi: http://doi.org/10.1111/j.1542-2011.2012.00176.x

[14] Goetsch, A. L., Kimelman, D., Woodruff, T. K. (2017). Uterine Fibroids. Fertility Preservation and Restoration for Patients with Complex Medical Conditions, 227-230. doi: http://doi.org/10.1007/978-3-319-52316-3_13

[15] Välimäki, N., Kuisma, H., Pasanen, A., Heikinheimo, O., Sjöberg, J., Bützow, R. et. al. (2018). Genetic predisposition to uterine leiomyoma is determined by loci for genitourinary development and genome stability. eLife, 7. doi: http://doi.org/10.7554/elife.37110

[16] Karlsen, K., Mogensen, O., Humaidana, P., Kesmodel, U. S., Ravn, P. (2019). Uterine fibroids increase time to pregnancy: a cohort study. The European Journal of Contraception Reproductive Health Care, 25 (1), 37-42. doi: http://doi.org/10.1080/ 13625187.2019.1699047

[17] Dolmans, M., Donnez, J., Fellah, L. (2019). Uterine fibroid management: Today and tomorrow. Journal of Obstetrics and Gynaecology Research, 45 (7), 1222-1229. doi: http://doi.org/10.1111/jog.14002

[18] De La Cruz, M. S. D., Buchanan, E. M. (2017). Uterine fibroids: diagnosis and treatment. American family physician, 95 (2), $100-107$.

[19] Sohn, G. S., Cho, S., Kim, Y. M., Cho, C.-H., Kim, M.-R., Lee, S. R. (2018). Current medical treatment of uterine fibroids. Obstetrics \& Gynecology Science, 61 (2), 192-201. doi: http://doi.org/10.5468/ogs.2018.61.2.192 